\title{
Investigating Neolithization of Cultural Landscapes in East Asia: The NEOMAP Project
}

\author{
Junzo Uchiyama $\cdot$ J. Christopher Gillam • Leo Aoi Hosoya • \\ Kati Lindström • Peter Jordan
}

Published online: 23 August 2014

(C) Springer Science+Business Media New York 2014

\begin{abstract}
The Neolithic is regarded as one of the most important developments in prehistory, a major cultural threshold marked by combined shifts in economy, technology, ideology, settlement and social organisation. Many foundational ideas about the Neolithic emerged within the context of European archaeology, and substantial work has now been directed at understanding how this 'package' of innovations appeared first in the Near East, and then dispersed steadily out into the rest of northwest Europe. Papers presented in this special issue are an output of the international NEOMAP Project (Neolithization and Modernization: Landscape History on East Asian Inland Seas) (2005-2012), which sought to apply two key approaches drawn from European Neolithic studies to the archaeology of East Asia: (a) the concept of Neolithization, defined as a long-term and historically-
\end{abstract}

\section{J. Uchiyama}

Research Institute for Humanity and Nature, 457-4 Kamigamo-Motoyama, Kita-ku, Kyoto 603-8047, Japan

e-mail: junzo@chikyu.ac.jp

J. C. Gillam

Savannah River Archaeological Research Program, South Carolina Institute of Archaeology and Anthropology, University of South Carolina, 1321 Pendleton Street, Columbia, SC 29208, USA e-mail: gillamc@mailbox.sc.edu

\section{A. Hosoya}

Centre for Global Human Resource Development, Ochanomizu University, 2-1-1 Otsuka, Bunkyo-ku, Tokyo 112-8610, Japan

e-mail: hosoya.aoi@ocha.ac.jp

\section{K. Lindström}

Division of History of Science, Technology and Environment, KTH Royal Institute of Technology,

Teknikringen 76, 10044 Stockholm, Sweden

e-mail: katli@kth.se

P. Jordan $(\bowtie)$

Arctic Centre, Groningen Institute of Archaeology (GIA), University of Groningen, Aweg 30,

9718 CW Groningen, The Netherlands

e-mail: p.d.jordan@rug.nl 
contingent process of culture-change; and (b), the contextual study of this process via the framework of cultural landscape research. This exercise has been highly productive, and provides new insights into a series of unique cultural transformations in East Asia, most of which have a very different sequence and character to those in the European Neolithic. It is hoped that, in turn, these comparative insights into the Neolithization of East Asian cultural landscapes will encourage those working on the European Neolithic to look back over their own regional datasets and critically reflect on some of their deeper assumptions about the internal logic and cultural content of the European Neolithic transition. Given the existence of so many fundamentally different kinds of Neolithic across the broader continent of Eurasia, the overall goal of this special issue is to re-kindle international debates about how best to explain each of these distinctive regional Neolithization trajectories.

Keywords European Neolithic · Neolithization · Hunter-gatherers · Transition to farming $\cdot$ Cultural landscape research $\cdot$ East Asia

\section{Introduction: Exploring Neolithization of Cultural Landscapes}

Something very important was gathering pace across the supercontinent of Eurasia during the early Holocene. New kinds of ceramic container technologies had already emerged among hunter-gatherer societies in the late Pleistocene, but were now being taken up more widely; many of these forager communities were abandoning a more mobile existence and becoming increasingly sedentary; hunting, fishing and gathering strategies were being supplemented by greater reliance on domesticated plants and animals, and many of these transitional economies were eventually replaced by a full-scale reliance on agro-pastoral farming as the primary mode of subsistence. This dynamic period witnessed a dramatic increase in material culture of a broadly symbolic nature, and also saw the emergence of entrenched social stratification and the increasing concentration of centralized political power within lineages and elites.

In European archaeology, these different innovations have often been linked together, and regarded as marking a general new threshold in human cultural development: 'The Neolithic'. Without doubt, adopting new technologies, settling down in the landscape, taking up farming and becoming 'Neolithic' was one of the biggest changes in human history, and had fundamental implications for diet, health, demography, social relations and human-environment relations that are still being played out today.

As knowledge of European archaeological sequences has steadily improved, later research has moved away from regarding the Neolithic as a new stage of human cultural development, and focused instead on the processes by which these changes came about. Increasingly, these are acknowledged to have been extended and regionally-variable cultural transformations. This shift in emphasis is captured by the more recent notion of 'Neolithization', which presents these transformations as a kind of generalised 'movement towards' an eventual outcome.

Thematically, the long-running debates about the significance and character of the Neolithic have also evolved and diversified: initial emphasis was placed on the economic transition to farming as the main driving force of Neolithization; subsequent research has argued that shifts towards a new Neolithic ideology preceded—and indeed facilitated — the later economic and technological shifts. 
A wide range of new theoretical approaches has also emerged through engagement with the enormous and still rapidly-expanding datasets on the European Neolithic. Given the sheer volume and diversity of this evidence, one of the most useful frameworks for combining these different theoretical perspectives and the multiple lines of evidence has been 'cultural landscape' research. Crucially, the cultural landscape approach is inherently flexible but also integrative: it provides scope for combining data on the ecological, economic and ideological dimensions to Neolithization; it is also question-led, and provides a means for investigating changes over time and at different social and spatial scales. For example, recent studies of Neolithization have often examined how local routines and practices were becoming caught up in the dynamics of longer-term cultural transformation.

Despite-or perhaps even because of - this exciting growth and diversification in archaeological data, explanatory models and interpretive frameworks, much current research into the European Neolithic remains steadfastly focused on developing ever more detailed treatments of local European datasets. The corollary to this is that, comparatively, less and less effort is now being directed towards understanding what was happening at around the same time in other parts of the wider Eurasian continent, of which Europe forms only a small western end.

This situation has many benefits, but also some shortcomings. On the one hand, in terms of sheer depth, human detail and theoretical sophistication, many current interpretations of the European Neolithic are among the most compelling archaeological accounts of cultural transformations and prehistoric social life in the entire world. On the other hand, the relentless focus on exploring ever more localised cultural sequences and their minute contextual details means that the exceptionally well-studied European Neolithization process is commonly presented as a somewhat self-contained and rather exceptional cultural development. For example, it is understood to have its own distinctive character, content and internal logic, which together determine the basic sequence and outcome of events: mobile foragers are either swept aside by a wave of agricultural migrants or themselves eventually become farmers; as part of this transformation, all the other main Neolithic attributes such as pottery, polished stone tools and settled village life are either spread by colonising populations, or adopted locally by indigenous foragers. Together, these developments lead to major 'shifts' in social life, culminating in the rise of a new kind of Neolithic cultural landscape.

Given the current state of knowledge and understanding of the European Neolithic, this special issue of the Journal of World Prehistory has two main aims. First, European Neolithic archaeology has, for over a century and a half, been a hotbed of theoretical innovation and intensive debate-could some of these ideas and approaches be applied to analogous datasets drawn from other parts of Eurasia?

In order to examine the potential benefits of such an exercise, this special issue applies the combined concepts of Neolithization (that is, the Neolithic transition viewed as a longterm process), and cultural landscape research (serving as an integrative framework) to the equally rich archaeological record of East Asia. For East Asian archaeologists, this application of these relatively new concepts and approaches to their own local datasets generates some exciting new ways of researching the trajectories of long-term culture change that were being played out in this region. The exercise succeeds in highlighting that a series of major cultural landscape 'shifts' were also the defining features of Neolithization in these easternmost regions of Eurasia.

But second - and of equal if not greater importance - these insights from the other end of the Eurasian continent also demonstrate that many of the Neolithization sequences 
found within prehistoric cultural landscapes in East Asia are very different to those identified in the European Neolithic. This should encourage European archaeologists to question many of their own implicit and deeply-held assumptions about 'logical' patterns of cultural variability and long-term change.

Overall, the main conclusion generated by this special issue is that there appear to have been a series of very distinctive kinds of long-term Neolithization processes, unfolding simultaneously across the Eurasian landmass during the Holocene. It is hoped that these papers initiate fresh debate about how best to engage with some of this broader-scale variability and regional diversity. Understanding and explaining the existence of these multiple Neolithics within the same Eurasian continent now emerges as a major challenge confronting any future attempt to write a truly comparative and contextual 'world prehistory'.

The remaining sections of this introductory paper contextualise this initiative in relation to older traditions of European Neolithic research, outline the main features of the cultural landscape approach, and explain why these concepts are useful for East Asian archaeologists seeking to make new interpretive sense of their own datasets. Emerging insights into Neolithization of cultural landscapes in East Asia are examined, and a series of general observations and future prospects are outlined in the conclusion.

\section{Older Traditions of Neolithic Research in Europe}

The study of the Neolithic of Europe has generated an enormous research literature, and this need not be reviewed in fine detail here. Instead, several salient developments can be identified, each reflecting general shifts in theory and debate, and the emergence of new phases of interpretation and understanding. For example, the Neolithic was initially understood as a distinct epoch of human cultural evolution, starting with Lubbock's technological definitions based on the presence of polished stone axes (1865, pp. 2-3). Later, understandings of the archaeology of this period were influenced by the foundational work of V. G. Childe (1957), who coined the term 'Neolithic revolution', to characterise a 'package' of innovations, including farming, pottery, polished stone tools and village life, carried forth into new areas of Europe on a rising demographic wave.

By the 1960s and 1970s, driven on by the ecological interests of the New Archaeology, the meaning of the Neolithic was shifting again, this time towards a more resolutely economic definition, which equated it with the transition to farming and a new economic mode of existence (Higgs and Jarman 1969). The revolution in radiocarbon dating also facilitated early attempts to plot the spread of Neolithic attributes from their origins in the Near East out across Europe (Ammerman and Cavalli Sforza 1984).

The 1980s saw two further contributions to these debates. First, Mesolithic huntergatherers were no longer regarded as passive observers of the transition to farming, but were increasingly acknowledged to have been capable of intensifying production even within the older foraging economy, adopting new technologies and developing more sedentary life-ways as 'complex' hunter-gatherers, long before the transition to farming (Price and Brown 1985; Zvelebil 1986). As contacts with early farming societies eventually emerged, hunter-gatherers were, in some cases, argued to be able to resist the spread of farming for long periods. The emergence of such forager-farmer contact zones also created opportunities for hunter-gatherers to control the speed and determine the sequence in which the full range of other Neolithic attributes were eventually adopted. 
The second contribution stemmed from a more theoretically-driven critique of the overarching economic focus of New Archaeology: instead, the Neolithic was argued to have been driven primarily by a major shift in human ideology, resulting from a novel form of domesticating mentality that enabled new kinds of materiality, and eventually agropastoral farming, to be fully embraced by indigenous hunter-gatherers (Hodder 1990). Many typical attributes of the Neolithic, such as domesticates, polished stone tools, monumentality and pottery, were regarded as a material expression of essentially the same kind of cognitive and ideological shift that was slowly spreading out across prehistoric Europe. Once cast as an economic revolution, the Neolithic had now become 'a new way of thinking' (Bradley 1998; Edmonds 1999; Hodder 1990; Thomas 1988, 1999; Tilley 1994).

Coeval with these theoretical debates has been cumulative growth in basic data on many local archaeological sequences, leading to the general acknowledgement that the Neolithic of Europe was far from a sudden or revolutionary leap from one generalised stage of human development to another, or a simple switch from mobile Mesolithic hunter-gatherers to settled farmers. Instead, it is now understood to represent a much longer-term, and inherently more historically contingent, process of transformation, one marked by both continuity and relentless change, generating substantial variability and local diversity. This new understanding is perhaps best captured by the notion of 'Neolithization', a transition towards the Neolithic, played out on the ground as a diverse, intrinsically local and historically-anchored process.

\section{Potentials of Cultural Landscape Research}

Given the ever increasing depth, breadth and resolution of archaeological data, combined with an ever expanding portfolio of theoretical perspectives, one of the key challenges in European Neolithic studies has been finding suitable interpretive frameworks that can successfully combine evidence for chronology, ecology, subsistence, ideology and social life, and transform these into accounts that both acknowledge the experience and agency of local households and communities and situate these within the broader-sweep historical transformations that were all central to the Neolithization of Europe.

To date, one of the more popular and productive analytical frameworks has been the 'cultural landscape' approach. This approach is, of course, not a direct product of European Neolithic studies, but has experienced widespread application within Neolithization debates at both local and regional scales. The key attraction of the cultural landscape concept is its inherent thematic flexibility along with its productive capacity for integration of diverse datasets, in terms both of specific content and of exploring variability and change across different spatial and temporal scales of analysis.

Importantly, the cultural landscape approach has diverse intellectual and methodological roots, which feed into this inherent flexibility (see Zvelebil 2003; and also: Bender 2006; David and Thomas 2008, with references). On the one hand, some of the more 'analytical' elements of the landscape approach can be traced back to the palaeoeconomy school, and to researching archaeological landscapes in terms of sites, access to natural resources and associated catchment areas, as well as in relation to palaeoenvironmental reconstructions. It is also linked to distributional approaches, which generate insights into the inhabitation phases of different sites and surrounding areas. On the other hand, many of the more 'interpretive' aspects of cultural landscape research emerged largely in Britain, and reflect partly an outgrowth of both traditional landscape history and its sentimental 
perspectives on the English countryside, but also a way of combining social theory and phenomenology with archaeological research (Zvelebil 2003, pp. 68-70). Many of these latter approaches also drew widely on perceptions of the landscape common to many indigenous peoples, particularly in Aboriginal Australia (e.g. Tilley 1994; Ucko and Layton 1999; Carmichael et al. 1994). According to this more interpretive research stream, meanings, values and power structures are embedded within the cultural landscape, and are reproduced through seasonal routines and shifting traditions of inhabitation (Barrett 1994; Bender 1993, 2006; David et al. 2014; Ingold 2000; Tilley 1994, 1996).

These combined analytical and interpretive elements therefore enable prehistoric landscapes to be comprehended in terms of both their ecological and cultural features, but also in terms of their deeper cognitive and indeed human experiential dimensions, all of which can be reconstructed across a wide range of inter-locking social, spatial and chronological scales. These reconstructions might range from micro-scale studies that emphasise the direct human experience of moving through a cultural landscape and encountering its features and elements, through to more macro-scale studies that approach landscapes as reflections of collective identities and shared ideologies, or perhaps as a cumulative product of the longue durée of social, economic or political institutions that directly impact the life-ways, experiences and opportunities of later generations.

For many archaeologists struggling to write holistic and more humanised accounts of such a complex, variable and multi-faceted phenomenon as the European Neolithic, the cultural landscape approach has solved many analytical and interpretive challenges. It has emerged as an essential tool for reconstructing basic chronological shifts in activity, technology, settlement, subsistence and palaeoenviroments, but has also facilitated exploration of cross-cutting themes such the local experience of historical change, and the slow integration of new traditions within older ways of acting in and on the world.

Landscape-oriented research has also provided a useful framework for exploring forager-farmer interactions and the shifting character of agricultural settlement, as well as the circulation of novel materialities, and the physical expressions of new worldviews and ideologies, which survive as monuments and other focal places. Thus, landscape research has probably been most useful as a medium of reflection, a way of combining different ideas, insights and perspectives within a deeper and more contextual interpretation of specific sequences of archaeological data.

\section{Current Trends in Neolithic Research in Europe}

Clearly, cultural landscape research has played a major role in the exploration of new perspectives on the European Neolithic, and generates many exciting opportunities for future case-studies and broader syntheses, but many challenges remain. In particular-and rather typical of any well-established field of research - many of the core debates, models and basic terms of reference within European Neolithic studies have remained surprisingly fixed, though other important interpretive trends are gathering pace. For example, in a review of future prospects for Neolithic transition studies in northwest Europe, Whittle (2007, pp. 621-626), highlights three general research trends. The first of these is the obvious desire to expand and improve the resolution of current archaeological and chronological datasets so that the older, and now highly-standardised, models of Neolithization can be tested at either regional or more local scales. These models regard Neolithization as a generalised process involving either colonisation by Neolithic farming populations or 
acculturation of indigenous foragers, reflected in the adoption of Neolithic economies, technologies and practices by local hunter-gatherers (2007, pp. 621-622).

The second is the emergence of a more 'integrationist' position, which regards Neolithization as a far more contingent and regionally-variable process, consisting of a wide mosaic of distinctive transitions, each defined by its own particular pace and cultural character, and each involving complex local patterns of migration, culture-contact and indigenous acculturation (see e.g. Zvelebil 2000, 2004, 2005). Although many older concepts and terms of reference, such as categorical distinctions between hunter-gatherers and farmers, are maintained, more generally, this position marks the maturation of attempts to interpret the local social contexts of Neolithization as played out in the different constituent parts of Europe. In fact, the integrationist perspective still enjoys widespread conceptual utility because many of its general empirical implications still need to be fully addressed via careful analyses of specific archaeological sequences (Whittle 2007, pp. 622-623).

The third of these trends is a more recent interest in investigating Neolithization on ever more local scales; coeval with this is the argument that European Neolithic debates have become so old and entrenched that the distinctions between such idealised and homogenised entities as foragers and famers need to rejected, and the entire historical process reconceptualised as a 'a spectrum of fusions' (Whittle 2007, p. 623). Drawing on the dramatic improvements in the resolution of chronological frameworks, the central concern here is to 'change the scales of analysis from the broad sweep and the long-term view to what was happening on the ground at any one time', the goal being to highlight the inherent contingency of events and developments (Whittle 2007, p. 623). This new approach directs attention towards understanding the actions and experiences of households and communities, from one generation to the next. It also abandons the writing of sweeping general narratives and concentrates instead on writing highly particularistic local histories, where there are no fixed identities or categories, just an endless fusion of negotiated meanings and shifting social identities (Whittle 2007, pp. 623-625).

In general then, studies of the European Neolithic have matured and diversified, and currently appear to be moving steadily away from the generation of the large-scale dispersal maps and culture-historical tables that paradoxically tend to summarise broad cultural change in a rather static fashion. In fact, the cumulative efforts of previous generations of researchers mean that many of these basic constituent time-space patterns and sequences are now relatively well-established in most of Europe.

Increasingly then, there is a trend towards the exploration of variability and contingency, either from an 'integrationist' or from a 'fusionist' perspective, both combined with a steady shift in analytical scale towards ever more localised accounts of Neolithic lifeways; in general, growing research efforts are being directed at 'writing much more varied and particularising histories of change' (Whittle 2007, p. 626), that is, towards understanding the significance of Neolithization in terms of events on the ground, and as played out within specific households and local communities.

\section{The European Neolithic: Time for Critical Reflection?}

Given this ongoing shift towards localised and contextual examinations of European Neolithization, where might fresh interpretive inspiration be sought? This emphasis on what might be termed historical particularism certainly builds on-and is indeed a logical extension ofolder research achievements and the exciting new refinements in radiocarbon dating methods. For example, many of the overarching patterns and sequences have now become much clearer, 
and so carefully describing and working through all the localised details of prehistoric lives caught up in broader-scale historical change does present an important challenge, and there are many different theoretical approaches for taking this agenda forward.

But if taken to its logical conclusion, where could this kind of Neolithic 'micro-histories' approach lead? To an endless accumulation of small-scale contextual interpretations, with no deeper historical research question ever defined? Archaeology is a broad discipline, increasingly capable of reconstructing micro-scale biographies of specific individuals, the dynamics of their prehistoric households and the constitution of their local communities, but it is also global discipline, one still tasked with identifying broad-scale patterns and explaining long-term cultural trajectories. It is these twin concerns that make the archaeological discipline truly distinctive, and give it what Trigger describes as 'a unique role to play in studying the full scope of human history and providing a general historical framework' (2006, p. 527).

Given these enduring research goals, are archaeologists in Europe somehow missing something important and distinctive about their discipline if their primary goal is now to look beyond larger historical patterns of variability and long-term cultural change, and to focus on exploring only the lived experiences of particular people at particular times in particular places? Whether this humanised narrative is presented in terms of rigidly separate forager and farmer histories, or uses the new fusionist approaches described above, the flip side of exploring the life-ways and experiences of human agency is that eventually_at some essential analytical threshold - these local actions start to feed into largerscale historical transformations. In this case, on-the-ground human agency was contributing directly to the unique historical phenomenon of the European Neolithic, which itself still needs to be explained on a general analytical scale.

Perhaps one of the main challenges to resolving this conflict between research priorities is that European Neolithic research (in contrast to that in many world regions) has entered a relatively mature phase of data gathering and interpretation. Paradoxically, this makes engagement with the deeper historical implications of on-the-ground human agency much less pressing, largely because the basic, macro-scale narrative of Neolithic cultural change is now taken for granted. The deeply engrossing details of humans, households and communities caught up in historical change are all that can be added, because the main structure, sequence and content of the general European Neolithic story line have already been universally accepted. For example, whatever the precise economic or ideological definitions of the European Neolithic, or the specific theoretical approach selected, archaeological scholarship is still underpinned by the basic argument that what happened in the Neolithic of Northwest Europe depended very directly on what had taken place somewhat earlier in the Near East. Moreover, for many regions, and especially in central and northwest Europe, the temporal brackets of Neolithization can also be fairly tightly defined, adding to the sense that the main Neolithic plot has already been revealedclearly, there were no farmers prior to 6000 cal BC and very few hunter-gatherers after 4000 cal BC (Whittle and Cummings 2007, p. 1).

In fact, this general explanatory framework actually conceals several more deeply-held assumptions about the basic source and logical sequence of developments. Yes, foragers inevitably became farmers; yes, the combined package of pottery, farming and village life was central to the spread of a new set of fully Neolithic life-ways. But did it have to be this particular way? Could other kinds of historical trajectory have emerged in Europe? In other words, a growing problem within European Neolithic studies is that this general narrative structure is now so widely accepted that it has moved beyond scope for any kind of deeper critical examination. 
However, as soon as the analytical focus is expanded beyond an increasingly particularistic analysis of European archaeological sequences, and shifted outwards to embrace a more comparative exploration of what was happening at around the same time in the many other regions of the Eurasian continent, it eventually becomes evident that prehistoric lifeways were being transformed along a series of strikingly different pathways.

Understanding and explaining the origins and co-existence of such contrasting cultural trajectories then emerges as an exciting interpretive challenge. Central to this task is the question of how the cumulative agency of individuals and communities living within specific landscapes and environments was able to generate such a diverse range of cultural transformations, not just in terms of the unique phenomenon of the European Neolithic, but also in terms of the diverse but coeval cultural developments taking place in the many other constituent regions of the Eurasian continent.

\section{Exploring Comparative Neolithic Insights from East Asia}

These general reflections have motivated the publication of this special issue. The goal is twofold. First, as a point of general departure, to look more generally into whether the Neolithic might have been a truly universal human phenomenon, that is, a single and culturally uniform global phase in 'world prehistory'. The easiest way to test this assertion is to apply some of the foundational concepts and approaches that emerged within the study of the European Neolithic to analogous areas. East Asia-that is, the region located at the opposite end of the Eurasian supercontinent and containing the modern nation states of China, Japan, and Korea, along with parts of the Russian Far East-has been selected because its many rich and well-documented archaeological sequences make it highly suitable for this carefully targeted comparative exercise.

For archaeologists working in East Asia, it is also a timely endeavour: the concept of Neolithization and the cultural landscape approach are relatively new here, and can be deployed at a time of growing local frustration with many of the older traditions of enquiry. These include culture-historical approaches, environmental determinism and unilinear models of cultural evolution, which no longer appear equipped to explain the observed patterns of cultural variability and change that characterise the archaeology of the region (Underhill and Habu 2006, p. 142). Experimenting with these (and perhaps other) ideas and approaches developed by archaeologists working in other world regions therefore holds deep attractions for many East Asian archaeologists.

Thus, the second aim of the special issue is to find new ways to understand local patterns of cultural diversity and transformation: this is definitely not a clumsy attempt to force-fit rigid European frameworks onto East Asian datasets. Although working creatively and constructively with these 'borrowed' concepts and approaches, all the papers in the special issue end up generating fresh insights into what often turn out to be very different East Asian Neolithization trajectories. These insights can, in turn, be fed back into the European debates examined above, raising new questions about familiar datasets, approaches and the accepted sequences of culture change.

More generally then, the overarching goal of this special issue is not to blithely export European interpretive frameworks to other regions, but rather to cultivate a broader and more reflexive cross-cultural exchange of ideas, approaches and insights pertaining to some of the most important cultural transformations in Holocene prehistory. This serves to benefit archaeologists working on similar periods, themes and datasets, at opposite ends of the Eurasian supercontinent. 


\section{The NEOMAP Project: Neolithization of East Asian Cultural Landscapes}

This special issue is an output of the NEOMAP Project, a major international research collaboration directed by Junzo Uchiyama from 2005 to 2012, which was hosted by the Research Institute of Humanity and Nature (RIHN), Japan. The guest editors and authors of all papers were members of the project. One of the central goals of NEOMAP was to understand major 'shifts' in the cultural landscapes of prehistoric Japan, while integrating them with case-studies in China, Korea and the Russian Far East. These combined initiatives were designed to provide complementary perspectives on and insights into the evolution of prehistoric cultural landscapes across East Asia.

In fact, NEOMAP's deployment of the term 'Neolithic' was a deliberately creative exercise from the outset. Attempting to sketch out even a simple working definition of a coherent 'East Asian Neolithic' was no easy task, but this relentless mismatch between models and data was, in the end, what made this research exercise so interesting from a global comparative perspective. As will become clearer below, a 'narrow' working definition of Neolithization might focus on understanding only the economic shift from foraging towards full-scale food production. But on the other hand, it might equally embrace the study of other important - and from a European perspective, potentially inter-relateddevelopments. These include the emergence of pottery, the rise of more sedentary settlement patterns, and the establishment of new, more stratified, social structures. These can be argued to form constituent elements in a 'broader' definition of East Asian Neolithization.

But almost as soon as this 'broader' Neolithization model is applied to specific regional sequences, it starts to break up into a series of disparate themes and individual developments. Even application of the 'narrow' economic model of the Neolithic transition becomes rather challenging, but in the end, this is where important comparative insights start to emerge. Central to exploring these patterns of diversity and change was the cultural landscape framework deployed by NEOMAP - transformations associated with the Neolithization process were linked back to substantive shifts in the structure and perception of local cultural landscapes.

To illustrate the general potential of the wider NEOMAP approach, the results of a central case-study are presented in this introductory paper. This examines the economic transition to paddy rice farming in Holocene Japan. In the other NEOMAP papers in this special issue, a similar approach is applied to other regional case-studies in order to understand how specific aspects or phases of the broader Neolithization process were unfolding across the rest of East Asia during the Holocene.

\section{Changing 'Routine-scapes' and the Transition to Farming in Japan}

There has been long-running discussion about whether prehistoric Japan experienced anything akin to a Neolithic Revolution (e.g. Imamura 1996, pp. 10-13). One of the most obvious entry points into these debates is to focus on the 'narrow' definition, that is, on the economic shift from hunting, fishing and gathering towards extensive reliance on paddy rice agriculture. According to established culture-historical sequences, the onset of a Japanese Neolithic could potentially be placed at the boundary between the end of the Jomon (hunter-gatherer) Culture (14000-1000 cal BC) and the start of the Yayoi (paddy rice farming) Culture (1000 cal BC to the third century AD); eventually, the Yayoi gave 
way to the Kofun period (third to seventh century AD), which was distinguished by a much greater degree of social stratification, as well as increasingly centralised political control.

Given the centrality of the Jomon-Yayoi boundary in Japanese Neolithic debates, the precise nature of this cultural transition has seen extensive investigation (e.g. Habu 2004, pp. 258-261), particularly in relation to regional chronologies, and to deeper patterns of continuity and change that affected the older subsistence economy. Also important is the influence of these economic changes on the apparently coeval rise of stratified farming societies in the Yayoi period. Regional chronologies, the pace and content of economic change, and the rise of social stratification have all therefore become key elements in current discussions about a Japanese Neolithic. However, exactly how these complex changes came about, and in particular, how the various social and economic transformations were related to one another, has yet to be clearly articulated.

The NEOMAP Project has argued that these important Jomon-Yayoi transformations can be viewed in new ways by applying a cultural landscape approach. For example, it is becoming evident that the introduction of paddy rice agriculture, via the Korean peninsula, from continental Asia eventually led to the formation of an entirely new kind of cultural landscape, fundamentally different to that of the preceding Jomon period (Uchiyama 2009, 2011). The ultimate outcome of this landscape Neolithization process was the emergence of a very different kind of society inhabiting a new, 'fully Neolithic' landscape. This involved material transformations in the built architecture and inhabited spaces of the physical landscape, along with major cognitive shifts and the establishment of fundamentally new routines for working the land, generating new patterns of social interaction, coordination and political control. The word 'eventually' is emphasised above because it became increasingly evident through the research undertaken by NEOMAP that it required considerable inter-generational adjustments for these new kinds of cultural landscape to emerge; understanding the finer contextual mechanisms of this cumulative transformation was therefore an important research theme within the project.

Developing new ways of approaching and integrating diverse lines of evidence was an essential first step. Over a series of publications, NEOMAP member L. A. Hosoya has developed the notion of 'routine-scape' (Hosoya 2008a). This has some general conceptual parallels with Ingold's notion of 'taskscape' (2000), but focuses more explicitly on understanding the routinized movements of objects, artefacts and resources over the cultural landscape during specific periods, as well as the ways in which the organisational structures and material settings of these routines can shift over time, requiring new kinds of human interaction, social organisation and cognitive adjustment. This more resolute focus on the integration of the material, social and cognitive aspects makes the concept of 'routine-scape' much more directly applicable to archaeological settings, because the physical record of these material flows and exchanges can be used to reconstruct the social interactions and routine practices that generated them, as well as the cumulative shifts in these practices over generations.

In particular, Hosoya's work has combined ethnographic parallels with closely contextualised analysis of archaeobotanical remains in order to reconstruct the general features of the Yayoi rice farming routine-scape and understand how it was slowly incorporated into older traditions of land-use (see Hosoya 2008b, 2010). This general paddy rice routinescape consisted of 'annual' and 'daily' cycles (Fig. 1). The annual agricultural cycle involves preparation of the paddy, the planting of rice seedlings and their repeated tending. The mature crop is harvested by picking off the 'ears' of rice, which are then sun-dried and stored. Keeping the rice in this husked format prevents wastage and rot. During daily routines of rice consumption, these ears are fetched from storage and pounded to de-husk 




CULTURAL LANDSCAPE

Fig. 1 Schematic representation of a possible Yayoi paddy rice-farming 'routine-scape'. This model (top) highlights the central role played by storage strategies in linking the 'seasonal' farming cycle with the 'daily' routines of rice consumption. In turn, all these routines would have been embedded within the local cultural landscape (bottom). For further explanation, see main text

the rice in preparation for cooking. Hosoya has emphasized that repeated use of storage facilities would have been central to these inter-locking annual and daily cycles, but also that the new rice farming routine-scape would have become embedded in an evolving cultural landscape, impacting in turn on its constituent physical, social and cognitive attributes. Importantly then, the adoption of paddy rice farming from mainland Asia during the Yayoi must have required a profound process of both mental and practical adjustment in the older Jomon routine-scapes.

Insights into this transformation process can be drawn from a NEOMAP case-study set in the Kinki district of the Japanese mainland (Fig. 2), one of the core areas of the new Yayoi cultural formation. The Yayoi is defined by the expansion of rice paddy farming and social stratification, and is followed by the Kofun Period, which is marked by the emergence of large mounds. These transformations can be viewed against the Kinki district's own culture-historical framework. Across most of Japan, the Yayoi period is generally divided into four sub-phases: the Earliest Yayoi (1000-800 cal BC); Early Yayoi (800-400 cal BC); Middle Yayoi (400 cal BC—50 cal AD); and Late Yayoi (50 cal AD_250 cal AD). A slightly different system has been developed for the Kinki district, dividing the Yayoi period into six sub-phases: Proto-Yayoi (1000-800 cal BC); Yayoi Stage I (800-400 cal BC); Stage II (400-200 cal BC); Stage III (200-50 cal BC); Stage IV (50 cal $\mathrm{BC}-50 \mathrm{cal}$ AD); and Stage V (50-250 cal AD). This different framework in Kinki district mainly reflects the fact that the 'Proto-Yayoi' is really only applicable to Northern Kyushu, 


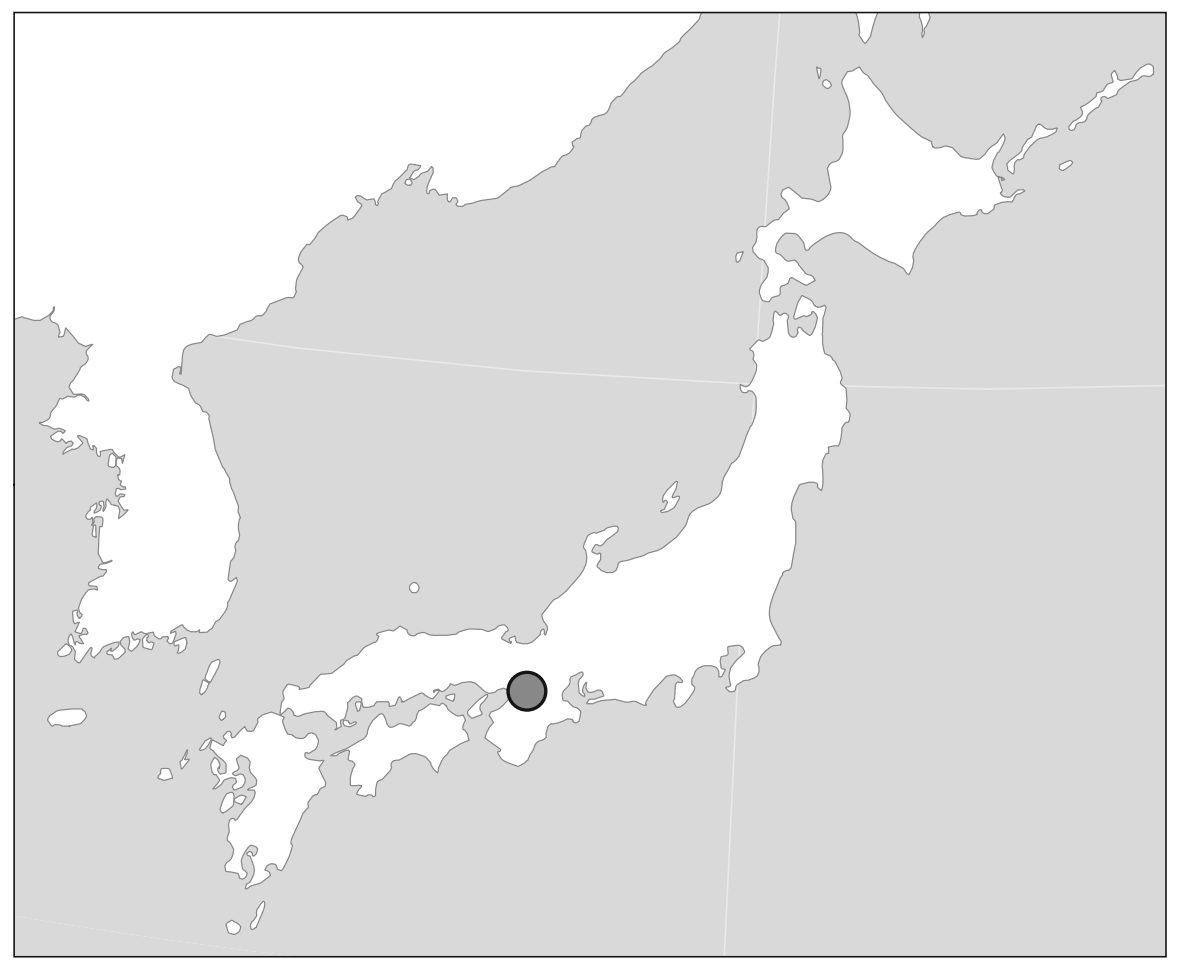

Fig. 2 Location of Kinki District, Japan

where rice paddy cultivation was first introduced into Japan; in Kinki district, rice farming came later, and so the Yayoi period begins here with Yayoi Stage I.

By combining data on archaeobotany, architecture, settlement systems and iconography, the NEOMAP Project was able to examine how shifts in plant storage and processing routines were closely linked to the entrenchment of social stratification during the latter half of the Yayoi period (Hosoya 2009a). Although evidence for differences in social status have been identified in the Jomon period (see Nakamura 2008), there appears to have been a fundamental shift in social organisation by the end of the Yayoi. NEOMAP's main argument was that the introduction of paddy rice agriculture eventually led to the formation of a new kind of management system for subsistence-related routines, all of which required a deeper shift in the perception of plant foods, but also triggered the eventual formation of a new type of elite, able to monitor and control the new rice farming routine-scape.

Storage strategies were certainly not a new phenomenon, and pits had been used widely in the preceding Jomon period (see e.g. Seguchi 2014). These were well-established hunter-fisher-gatherer societies practising delayed-return economic strategies, which involved long-term investments in fixed locations to balance out seasonal shortfalls in wild resources (see Habu 2004; Seguchi 2014). Interestingly, continuity in such Jomon-type storage technologies can still be noted at the end of Yayoi Stage I (c. 800-400 cal BC); these chozo-ketsu storage pits were generally located outside settlements and used to store both wild nuts and plants, as well as small quantities of the newly-adopted rice crops (Hosoya 2002, 2008a). 


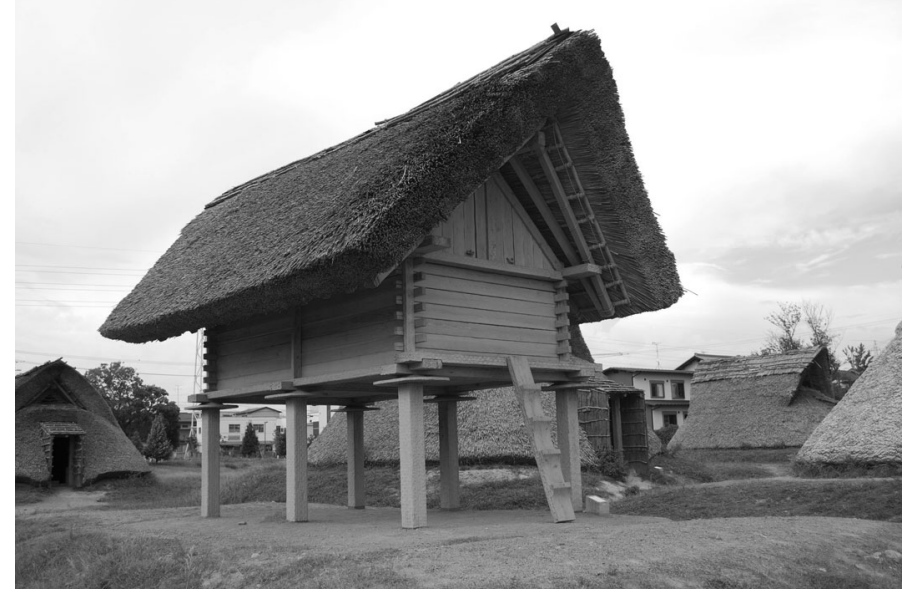

Fig. 3 A reconstructed example of a Yayoi 'raised-floor rice granary' at the Toro site (reproduced with permission of Shizuoka City Museum, Shizuoka Prefecture, Japan)

However, from Yayoi Stage II (c. 400-200 cal BC) onwards these chozo-ketsu pits become much less common, at a time coinciding exactly with the appearance of a new kind of raised-floor storage building, one most likely adopted from mainland Asia as part of the package of rice paddy farming practices (Fig. 3, top). The apparently simultaneous reduction in Chozo-ketsu pits and increase in these raised-floor buildings-a process in some cases observable within a single settlement-shows a major change in food storage strategies. Perhaps even more significant is the fact that rice remains also disappear from the few Chozo-ketsu contexts still in use, suggesting that rice storage and consumption routines, in particular, were starting to separate out and become re-focused on the repeated use of the new raised-floor 'granaries'. In turn, this hints at a growing cognitive separation between use of 'wild' plant resources and the novel 'domestic' rice crop produced by the paddy field. Within villages, these raised-floor granaries must also have been emerging as a much more conspicuous architectural element of the everyday routine-scape than the more discreet and perhaps even hidden chozo-ketsu pits located beyond the settlement (Fig. 3). This combined evidence suggests the early stages of the slow establishment of an entirely new kind of rice-focused routine-scape within the older Jomon cultural landscape.

During Yayoi Stage III (200 cal BC_-50 cal BC), further shifts take place as the raisedfloor granaries start to be grouped into specific areas, but only within the larger moated settlements; most of these 'communal' storage zones are also surrounded by a ditch, marking them out as an entirely separate activity area (Hosoya 2002, 2009b). People would have gone regularly to this granary area to fetch their daily supplies of rice, and perhaps to perform other rice-related activities. The routines of rice consumption were clearly shifting from more private, household-scale activity towards a much more public, increasingly centralised activity, whether or not practical crop production and storage were being managed still at a household level or more communally. There is also a hint of the emergence of new socio-political opportunities - certain individuals or lineages may have started to gain influence and power over others by manipulating the daily conduct and significance of increasingly public routine. 


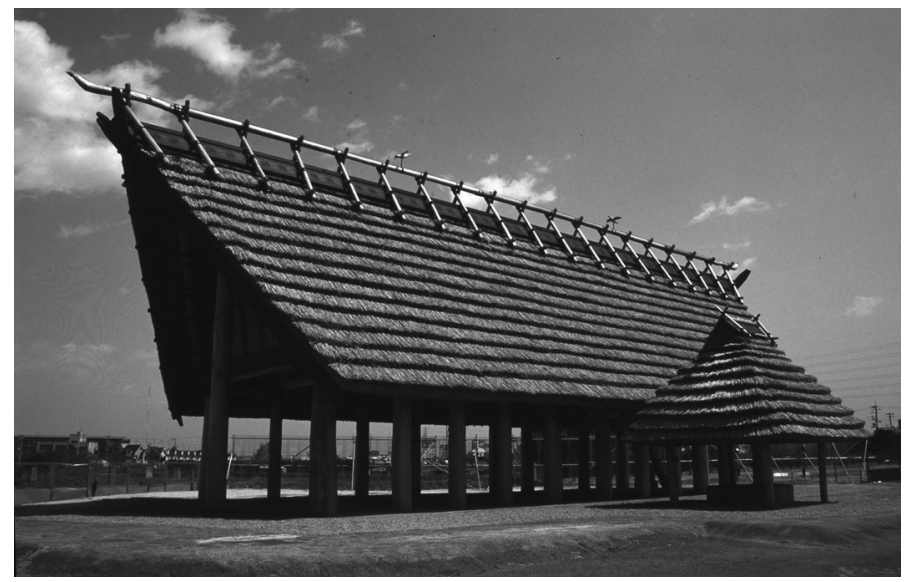

Fig. 4 The reconstructed 'central building' at the Ikegami Sone site (reproduced with permission of the Izumi City Board of Education, Osaka Prefecture, Japan)

Interestingly, from Yayoi Stage III through to the Yayoi Stage IV (50 cal BC -50 cal AD) many of these larger moated settlements in the Kinki district start to display evidence for another kind of communal space. This has been termed the 'central arena' and includes a new kind of 'central building', substantially larger than the other structures, with many distinctive features. In Kinki district, these buildings appear to derive their style from the raised-floor granaries, but are built to much larger dimensions, perhaps serving as an enlarged symbol of the crucial storage phase in the annual rice-farming routine-scape (Fig. 4). Moreover, there is evidence that certain rice-processing activities were conducted around the central building. For example, at the Ikegami Sone site, Kinki district-a typical Yayoi large, moated settlement site-archaeobotanical research indicates that rice de-husking occurred at the central building (Hosoya 2009b).

In addition, iconographic evidence from Yayoi Stage III through to Stage IV indicates that this de-husking stage was taking on new significance. Drawing on ethnographic parallels with traditional rice farming societies in East Asia, Hosoya (2008b, 2010) was able to suggest that de-husking of the dried rice ears was an important last step in converting stored plant resources into rice grains fit for human consumption. Further iconographic evidence starts to hint that this ritual significance was later being transferred to the large central building, where at least some of these de-husking activities were conducted. In this way, one of the most important elements in the entire rice farming routine-scape was slowly becoming associated with the central building.

Even more intriguing in the local iconography are depictions of a new kind of person in a special 'winged' costume, often in close association with images of the central building, which itself was a deliberately enlarged version of a raised-floor rice granary (Hosoya 2009b). Perhaps in the earlier stages of routine-scape transformation, this special person was just a general coordinator for the practical activities being conducted around the central building. Over time, however, and as events at the central building increasingly became the symbolic culmination of the entire paddy rice routine-scape, these special figures may have become increasingly imbued with ritual authority. Perhaps not surprisingly, these central buildings eventually evolved into the residences of the Oh ('king') 
elites in the following Kofun period, while the arenas went on to serve as the location of the raised-floor granaries (Hosoya 2009b).

By employing Hosoya's concept of routine-scape, the NEOMAP Project was able to suggest that, in the Kinki district, the shift towards full Neolithization of the cultural landscape started during Yayoi Stage II, but only really gathered pace from Yayoi III through to Yayoi IV, culminating in the rise of increasingly centralised and socially stratified ('Neolithic') rice-farming societies. In contrast, the initial presence of a few of the earliest domestic rice grains along with wild plant foods in the Chozo-ketsu storage pits points to strong continuities from the preceding Jomon period in the perception and processing of plant foods, a situation that extended well into Yayoi Stage I.

In general, then, even if the very earliest onset of landscape Neolithization is placed at the very start of the general economic shift from hunting and gathering to paddy rice farming, it is clear from NEOMAP's research that the transition from the Jomon to the Yayoi cultural landscape was, in fact, a much more protracted process than has hitherto been acknowledged. Clearly, the new routines and practices associated with rice cultivation, processing and storage needed substantial periods of multi-generational time to become fully embedded into older cultural landscapes. Nevertheless, the emergence of a new routine-scape unleashed powerful transformative forces, leading to the eventual formation of a highly stratified agrarian community entirely different to that of the preceding Jomon.

\section{NEOMAP: Exploring Neolithization of Cultural Landscapes Across East Asia}

If attempting to locate the onset of a 'Japanese Neolithic' at a simple economic turning point reveals a complicated process of continuity, adjustment and gradual change, then what of the other definitive attributes of the European Neolithic, such as the emergence of pottery and the rise of village-based sedentism? What role is played by these other 'Neolithic' elements in the transformation of cultural landscapes in East Asia?

There is now compelling evidence that East Asian hunter-gatherers had already innovated pottery towards the end of the Pleistocene (see Craig et al. 2013; Jordan and Zvelebil 2009; Kaner 2009; Gibbs and Jordan 2013). Many other important Neolithic-type developments, such as increasing sedentism, economic intensification and deep shifts in social organisation also followed during the Holocene, linked in turn to tangible changes in the cultural landscape; exploration of these latter Neolithic attributes provides the focus for the six other papers in this special issue.

Thanks largely to the efforts of the NEOMAP Project, the concept of 'cultural landscape research' is now starting to provide East Asian archaeologists with a new interpretive framework within which different lines of evidence pertaining to chronology, ecology, settlement, subsistence, technology and ideology can be productively combined. The introduction of the notion of 'Neolithization' by the project has been equally significant, giving scope for approaching the emergence of the Neolithic as an inherently long-term process of culture change rather a uniform stage of social evolutionary development. This is important because the rich archaeological record of East Asia has enormous potential for deepening our understanding of 'the dynamics of long-term change in early communities' (Underhill and Habu 2006, p. 142).

Authors of the individual case-study papers were invited to apply these twin concepts to local archaeological sequences in China, Korea, Japan and the Russian Far East. This integrated approach represents a major shift away from many of the more established 


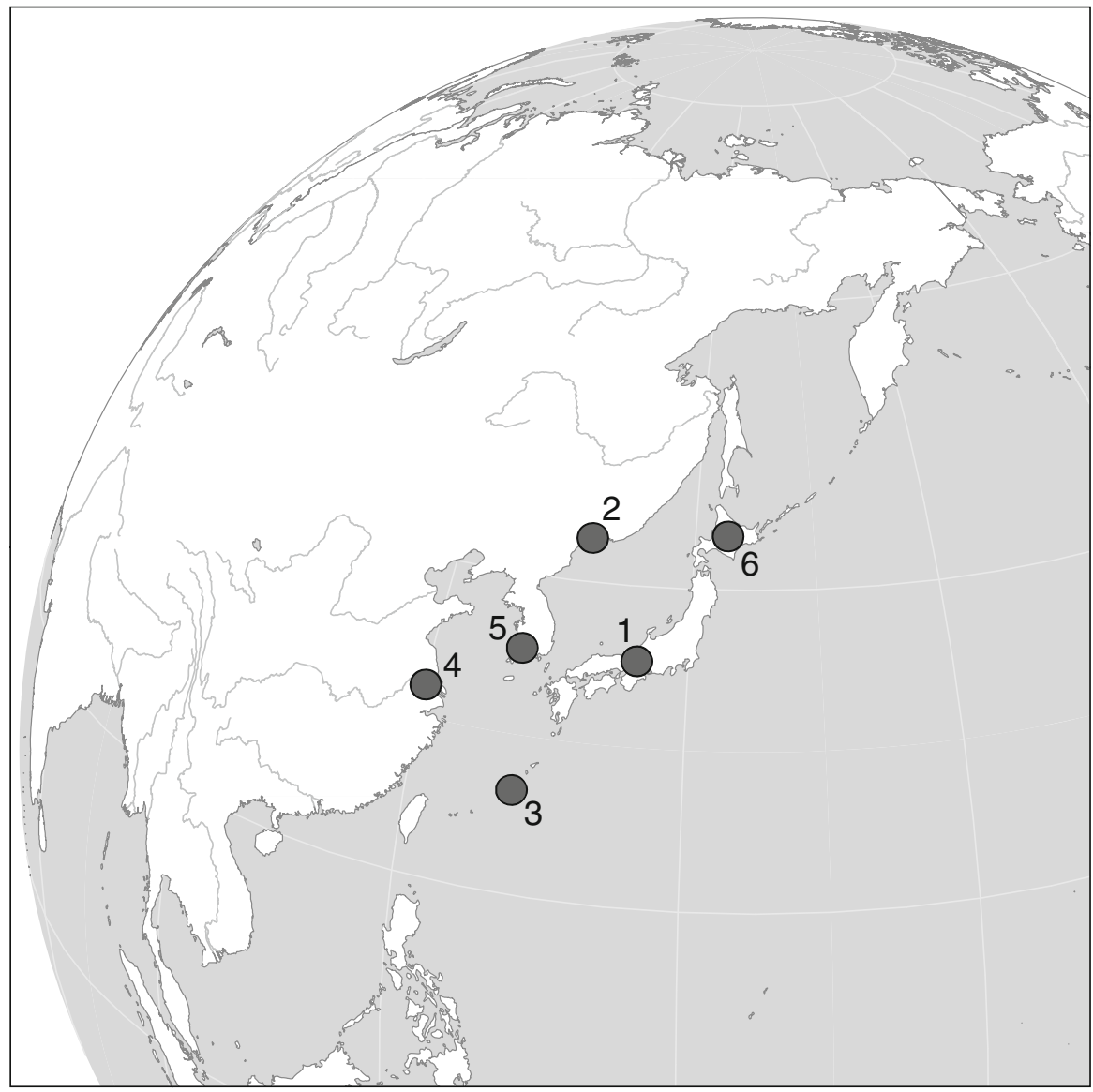

Fig. 5 The NEOMAP Project. Comparative case-studies of cultural landscape Neolithization in East Asia: 1 Lake Biwa, Japan (Seguchi); 2 Boisman Bay, Russian Far East, Russia (Popov et al.); 3 Ryuku Islands, Japan (Ito); 4 Yangtze River, China (Makibayashi); 5 Korea (Kim); 6 Hokkaido, Japan (Onishi)

archaeological research traditions in each of the region's modern nation states. In general-and despite significant intellectual differences - these national research traditions have tended to focus on describing homogenous entities and archaeological cultures, as well as what have been assumed to be universal stages of social evolutionary development (see below). Finally, the approach provides new scope for exploring East Asian cultural variability and change at an inter-locking range of scales, linking local shifts in landscape inhabitation to major long-term transformations.

These six papers present a broadly representative range of case-studies from China, Japan, Korea and the Russian Far East (Fig. 5). For coherence, they are ordered within a general chronological sequence, starting with the cultural landscapes of hunter-fishergatherer societies of the earlier and mid Holocene (Seguchi; Popov et al.; Ito); moving on to examine cultural landscape formation among early farming communities in China (Makibayashi); and then to the investigation of later socio-political transformations in landscapes associated with fully-developed farming societies of the Korean peninsula 
(Kim). The final paper (Onishi) examines the contrasting impacts of Neolithization on communities living in northern environments, where some of the most important landscape shifts are associated with existing hunter-fisher-gatherer communities adjusting their subsistence activities towards external trade demands rather than the local adoption of farming.

This tightly integrated collection of papers employs a range of complementary approaches and perspectives as shared points of departure to explore how Holocene cultural landscapes across East Asia were impacted both physically and cognitively as local communities participated in a wide range of economic, social, ideological and technological transformations.

At one level, the papers generate contrasting insights, which reflect the current state of research in the various modern nation states and case-study regions, as well as the inherent character of local archaeological records, and the very different theoretical and cultural paradigms within which these archaeologists have been trained and continue to operate. But at another, perhaps more important, level the papers remain united by similar concerns with exploring cultural variability and its relationship to processes of long-term historical change across a number of interlocking social, spatial and chronological scales.

Importantly, the papers clearly define their notion of the Neolithic from the outset, and thereby avoid imposing notions of a universal 'Neolithic revolution' on to their data. They seek instead to work through the local details of human-landscape relations in order to identify landscape 'shifts', which are taken to be 'thresholds' or 'tipping points' within the broader Neolithization process. This is an important strategy, because it means that the inherently different character of these shifts can be drawn out, emphasising the sense that there were many different Neolithic transitions across East Asia, each with a unique character, a point that European archaeologists should take note of, and one that is returned to below.

Seguchi's opening paper examines the cultural landscapes of Jomon hunter-fishergatherers living around Lake Biwa in Japan. He argues that Western models of the Neolithic fit poorly on to this local archaeological record: the Neolithic attribute of pottery was already present in the late Pleistocene, and the first farming economies emerge very much later, as discussed in the previous section. In that sense the Japanese Jomon is not really Neolithic, at least in the narrow economic (i.e. farming) sense, but nonetheless, it is characterised by many other 'Neolithic' attributes, such as early and very widespread use of pottery, and also, in later phases, the emergence of enduring village-based communities within densely-settled cultural landscapes. In fact, it is this latter 'shift' that becomes central to Seguchi's analysis of landscape Neolithization; his main concern here is to understand 'alternative pathways' to settled village life that do not necessarily require a coeval transition to agriculture.

The cultural landscape framework is foundational to his analysis: the ecological environment around Lake Biwa is highly structured, with seasonally-available plant, fish and animal resources falling into a series of discrete zones. Seguchi argues that Jomon communities could mediate the effects of these ecological factors by developing new settlement strategies, which eventually made widespread sedentism possible. Working through the archaeological evidence for settlement, subsistence, storage and mobility, he is able to establish that the earliest sedentary settlements emerge first in the few parts of the landscape that are located at the interface of different aquatic and terrestrial resource zones. In effect, these unique locations solve all the primary problems of seasonality and the highlystructured ecological landscape: a range of complementary resources is available yearround within a short distance of each settlement. However, Seguchi argues that this 
remains a rather passive strategy, as the zoned ecology still determines which areas are suitable for this new kind of settled village life.

As population pressures increase, the most substantive cultural landscape shift takes place. Jomon communities begin to develop other technological and mobility strategies that enable them to fully resolve the deeper challenges generated by the inherent seasonality, structure and zonation of the ecological landscape. These solutions unleash new potentials for the establishment of permanent village settlements across many other parts of the landscape. Indeed, it is this more widely settled landscape, according to Seguchi, that forms the first fully cultural landscape, reflecting a new level of human intervention in solving many of the ecological landscape's natural challenges, enabling the harvesting and storage of complementary kinds of wild resources by foragers living in permanent villagetype settlements. He concludes that future East Asian studies of Neolithization should use these themes in a more heuristic manner, that is, with the aim of revealing inherent diversity in patterns of culture change-whether in exploring alternative pathways to sedentism, shifts in subsistence, or the uptake of new technologies such as pottery-and not seek to impose general Neolithic models developed in Europe on other world regions.

Popov et al. provide an ambitiously holistic interpretation of landscape Neolithization in the Primorye region of the Russian Far East. For international readers, this paper also provides an important overview of Soviet approaches to the Neolithic, which were dominated by a unique blend of social evolutionary and culture-historical theory. Previously then, the Neolithic was regarded in Soviet/Russian archaeology as constituting a uniform stage of technological development marked by the emergence of pottery (and not agriculture). For other complex reasons, the themes of ecology and adaptation were not generally explored within Soviet/Russian archaeology, and nor were the themes of prehistoric ideologies and world views. It is these older academic frameworks that the current paper seeks to transcend; it quickly becomes clear that opportunities generated by the combined concepts of Neolithization and cultural landscape research, central to the NEOMAP Project, are rapidly transforming many of the older traditions of archaeological interpretation in the Russian Far East.

This deployment of the cultural landscape framework makes it possible to approach the Neolithic as a long-term and more embracing cultural process, involving shifts in subsistence, settlement and world view. However, Primorye and many other parts of the vast territories of Siberia and the Russian Far East remain very sparsely populated even in modern times, with many having seen only a few decades of expeditionary archaeological fieldwork to establish basic sequences and cultural affiliations. Thus, Popov et al. argue that the most meaningful progress on these key themes can be made by focusing current research efforts on the sites with the richest archaeological potential; their inter-disciplinary approach to landscape Neolithization is focused on understanding the mid-Holocene hunter-fisher-gatherer site of Boisman II, located in southern Primorye in the Russian Far East.

The authors regard this important site — and the wider Boisman Culture-as manifesting a new kind of Neolithic social and cultural adaptation that emerges in the ecologically productive coastal and lagoon environments during periods of higher sea levels, providing scope for alternative pathways towards economic intensification without the emergence of an agricultural food-producing economy. At the main Boisman II site, a complex of large shell middens mark communal feasting locations, and also serve as highly visible monuments for the commemoration of ancestors and the structured placement of the dead.

The rise of these new cultural landscape features appears to be a reflection of the growing attachment to specific 'focal' places within the seasonal round. However, there is 
also a 'dark side' to this process of cultural landscape Neolithization: besides a greater symbolic attachment to such ritual places, there is widespread evidence in the burials for growing disparities in individual wealth; widespread inter-personal conflict; and often violent death, perhaps all indicative of growing social tensions resulting from territoriality and ownership struggles over the most productive resource locations. Overall, this paper charts a major break from older archaeological research traditions, and exemplifies the results of a new generation of innovative post-Soviet archaeological research that is currently underway in the Russian Far East, using an approach which could easily be expanded to include both later periods and adjacent regions of the former USSR.

Similarly, Ito's paper attempts to understand the cumulative Neolithization of hunterfisher-gatherer cultural landscapes, but this time focusing on the emergence of forager sedentism in the Ryukyu Islands. This archipelago stretches between present day Japan and Taiwan, and is located at the ecological intersection of the temperate forest zone, with its abundant food resources, and the northern limit of coral reefs, which afford easy access to abundant coastal and lagoon resources. Long considered to represent a simple southern extension of the culturally uniform Jomon sequences of Japan, this remote insular setting, Ito argues, had its own cultural dynamism, which eventually led to the formation of a unique 'Forest and Coral Reef Neolithic Culture', a process marked by two major shifts in the local cultural landscape, each contributing to a unique trajectory of historical development.

After a long period in which people move between relatively fixed sites in the landscape, the hill tops-which command the entire resource landscape, providing unobstructed views of coastal fishing areas and easy access to the mosaic of inland resourceseventually become the focus of more permanent settlement. It is interesting that this period is also marked by evidence of growing human manipulation of the island environments, including deliberate forest clearance, and perhaps even small-scale cultivation.

Later periods, however, are marked by a new shift towards sedentary settlements, now located along the coastlines. External factors are at work here as the island communities are becoming increasingly integrated into long-distance exchange networks with the ricefarming Yayoi Culture that eventually emerged in mainland Japan. These intercultural contacts result in the rise of what might be termed 'commercialised' foragers, rather than a full local transition to agriculture, a pattern repeated in the northern island of Hokkaido (Onishi), as discussed below. Once again, the cultural landscape framework provides useful scope for making sense of these long-term transformations within a remote insular setting.

The next two papers switch the focus from hunter-fisher-gatherer societies to exploring the evolving cultural landscapes of early farming communities, each adding a number of related insights. Makibayashi's paper examines the Neolithic landscapes of China. Traditionally, Chinese archaeologists have argued for an enduring dichotomy between the northern 'millet' Neolithic and a southern 'rice' Neolithic, together with strong internal uniformity within each of these different cultural phenomena. Makibayashi tests the veracity of these older models by employing a cultural landscape approach that investigates variability in early agricultural technologies associated with the cultivation and processing of rice. On the basis of these results, he identifies two very distinct ways in which the routines and practices of rice farming were being embedded into the local cultural landscapes, one on the lower Yangtze, and another on the middle Yangtze. On this basis, Makibayashi argues convincingly for the existence of much greater 'internal' variability within the uniform 'rice' Neolithic than had hitherto been acknowledged. 
Kim's paper brings Neolithization debates back full circle to the theme of how the shifts in cultural landscapes triggered by new agricultural systems might actually lead to an entrenchment of social stratification. His case-study examines the culmination of such socio-political transformations in Korea, and he charts the growing domination of increasingly stratified societies through the political strategies pursued by emerging elites. According to Kim's analysis, these established interest groups deliberately manipulate the cultural landscape in order first to mask, and then to legitimate, this growing social inequality. Although this requires negotiation and accommodation of change across all levels of society, Kim sees this as a process being driven primarily by the top-down agency of the emerging elites, facilitated in part by the rather passive compliance of those lower down the social scale. These dynamics result in a growing centralisation of power and control, and therefore serve to highlight how the latter stages of Neolithization may eventually feed through into the early stages of state formation.

The final paper by Onishi provides a thoughtful and provocative exploration of other potential outcomes of such regional Neolithization processes. Rather than focusing on areas like China and much of mainland Japan that eventually adopt farming and later experience the rise of early states, he reflects instead on the fate of prehistoric huntergatherer societies which do not make this 'full' transition to agriculture, but remain largely reliant on foraging right through to the historic and indeed ethnographic periods. Do such societies somehow fail to make a Neolithic transition, remaining in an earlier Mesolithic or even Palaeolithic mode of existence? Onishi argues not, and highlights the complex and dynamic historical trajectories that have characterised hunter-fisher-gatherer populations in Hokkaido, northern Japan.

Onishi identifies a major shift in Hokkaido's cultural landscapes between the Epi-Jomon and the Satsumon periods (that is, around the seventh century AD). He argues that this was primarily the result of increased contact with the politically-centralised and highly stratified farming societies which were by this time well established across other areas of Japan; in particular, these contacts led to the increasing commercialisation of the local salmon fisheries in Hokkaido, which was linked in turn to the formation of new kinds of exchange relationships, and the rise of inter-regional economic specialisations across much of the Japanese archipelago.

This is an important case-study because it explores some of the strategies open to prehistoric forager societies who may, for a range of complex reasons, be either unwilling (for cultural or symbolic reasons) or unable (perhaps for ecological and climatic reasons) to 'go over' to a Neolithic farming way of life (Whittle and Cummings 2007). Like the earlier paper by Ito on the Ryuku Islands foragers, this contribution raises more general questions about the long-term historical fate of hunter-gatherers living in the different forager-farmer contact zones that opened up in many temperate and higher-latitude environments during the Holocene.

For example, across much of prehistoric northern Eurasia, from the Baltic through to the Pacific, these kinds of contacts eventually led to the growing commercialisation of northern hunter-fisher-gatherers. This process accelerated in later historical periods, especially in relation to state expansion into northern areas, and involved a growing trade in fur, fish and other northern resources (Zvelebil 2008; Hudson 2014; Jordan 2011, pp. 28-30; 2014, pp. 912-915; Taavitsainen 2014). In general, then, this Hokkaido case-study maps out yet another potential historical trajectory that is triggered by the onset of regional-scale processes of Neolithization, one that exhibits broad similarities with those also unfolding across much of northern Eurasia. 


\section{From Europe to East Asia: One Neolithic or Multiple Neolithics?}

The NEOMAP Project sought to apply the twin concepts of Neolithization and cultural landscape research to the rich archaeological record of East Asia. Given the results and insights reviewed above, this exercise has clearly succeeded in producing a new kind of understanding of the historical dynamism of small-scale societies within prehistoric East Asia, all of which transcend, in one way or another, many of the more established traditions of archaeological enquiry, opening out exciting future potential for similar research across the wider region.

This special issue has also aimed to link these NEOMAP findings back to a more international archaeological readership, since these interpretations can also be cast as a series of comparative insights into processes of mid-Holocene culture change. As discussed above, these may well have particular utility for European archaeologists, who will no doubt be familiar with the general themes of cultural landscapes and Neolithization, but will be less familiar with, and perhaps even surprised by, the results that emerge when these interpretive frameworks are applied to East Asian archaeological sequences.

But to what extent has this been a productive exercise? As many of the papers are quick to highlight, the concept of the 'Neolithic' clearly has a European origin, and it therefore comes as no surprise that it fits rather poorly to the East Asian sequences, especially if the Neolithic is taken to be a coeval appearance of a tightly integrated 'package' of innovations: farming, pottery and village-based sedentism. Clearly, Holocene societies in East Asia experienced many very different forms of socio-economic, technological and even ideological transformation. All these 'Neolithic' attributes eventually emerged, but generally at very different times and according to rather different sequences than in Europe: pottery container technologies emerged very early among East Asian foragers (Jordan and Zvelebil 2009; Cho and Ko 2009; Kaner 2009; Habu 2014, p. 508); the full transition to farming often came very late; village-based sedentism probably appeared somewhere between these two developments. Many of these features of the local archaeological record show East Asian Neolithization as a highly protracted and, in the main, rather disconnected set of developments; this stands in contrast to the dispersal of an integrated 'package' of Neolithic innovations, which is the case in much of Europe. Importantly then, many papers also tend to re-cast the examination of cultural landscape Neolithization in East Asia as the study of extended hunter-fisher-gatherer cultural trajectories.

In seeking to explore the cultural dynamism of these Holocene East Asian huntergatherer societies, the flexibility of the cultural landscape approach also enables authors to single out one specific aspect of the Neolithization process, such as the emergence of sedentism, or a more protracted transition to farming, or the entrenchment of social stratification, and then subject this single Neolithic 'attribute' to a more sustained contextual analysis. The authors demonstrate that important cultural landscape 'shifts' are linked to all three of these developments.

For example, some of the most important landscape shifts are linked to the rise of a more sedentary hunter-gatherer existence, coeval with economic intensification and greater modification - and even mastery — of the cultural landscape (Seguchi; Ito; Popov et al.). Pottery having been innovated long before the start of the Holocene, its widespread use (along with the emergence of settled village life long before the transition to farming) is a distinguishing feature of this unique East Asian 'hunter-gatherer'-or 'hunter-fishergatherer'-Neolithic trajectory. One might equally talk about these trajectories in terms of an 'aquatic Neolithic' (e.g. heavy reliance on [shell]fish or marine resources), an 'arboreal Neolithic' (e.g. a major role for nut harvesting and other plant resources), or indeed a 'coral 
reef Neolithic' (Ito), all of which become well established long before any hint of a transition to agriculture.

Whatever the precise terminology, there are many striking examples of this kind of long-term forager trajectory, including the Japanese Jomon (Seguchi), the Korean Chulmun (Kim; see also Underhill and Habu 2006; Habu 2014, both with references) and the Neolithic cultures of the Russian Far East (Popov et al.). And as many papers examine, this growing hunter-gatherer sedentism has important implications for the cognitive and commemorative dimensions to cultural landscape, which in many cases leave clear archaeological signatures in the form of enduring focal places. These extended Holocene hunter-gatherer cultural trajectories are probably where the greatest contrasts to the European Neolithic sequences start to emerge.

In East Asia, the eventual transition to agriculture remains, of course, a fundamentally important development, and is linked clearly to the shift towards new kinds of sociopolitical landscape, underpinned by control of agricultural and symbolic resources by emerging elites. But NEOMAP's landscape-grounded approach demonstrates that these processes needed considerable time to become fully embedded within the routine-scapes of local social life, as seen in the case-study from Japan's Kinki district (see above). It is also evident that the cultural landscapes of early agricultural systems are highly variable, even within 'uniform' culture areas like the rice Neolithic of the Yangtze. Thus, the inherent diversity in East Asia's 'hunter-gatherer' Neolithics is matched by an equal degree of variability in East Asia's 'farming' Neolithics. Such insights may be of interest to European archaeologists seeking to understand the cultural significance and local social meanings associated with similar cumulative shifts in subsistence.

Finally, cultural landscape shifts in remoter archipelagos (the Ryuku Islands, see Ito) and across more northerly regions (Hokkaido, see Onishi) appear to exhibit a different historical dynamic, in which hunter-gatherers generally integrate more closely into regional exchange networks linking them to later Neolithization processes, such as increased stratification and centralised political control, in areas further south. This triggers a growing 'commercialisation' of many of their older foraging activities (e.g. fur and fish), casting them as new kinds of inter-cultural specialisations within wider exchange networks. However, the logic and structure of these latter trajectories only makes sense if considered on a wider regional, and even continental, scale, in order to fully understand the deeper implications of Neolithization processes operating on hunter-gatherers living in remote or marginal areas. Similar insights are now emerging from prehistoric and historic northern Europe (e.g. Zvelebil 2006, 2008; Taavitsainen 2014).

In sum, the observations produced by the NEOMAP Project serve as a sustained critique of the more stadial and social evolutionary notions of Neolithic development that prevail in many parts of East Asia. They also open to renewed scrutiny the general assumption that the archaeological record should consist of large-scale, coherent cultural entities that endure across time and space. Instead, NEOMAP's aspiration to reconstruct local patterns of landscape Neolithization provides fresh scope for exploring the variable character of many local cultural trajectories.

What also emerges from all the papers in this special issue is a general sense that new cultural traditions took time to become embedded within the routine-scapes of older cultural landscapes, rather than occurring as sudden or revolutionary changes. Overall, such transformations are portrayed as slow and inherently humanised processes, leading in time to diverse and historically contingent local outcomes. In fact, the growing realisation of the inherent dynamism and cultural variability across the 'multiple Neolithics' of East Asia is probably the most important insight to emerge from all the papers; it provides a useful 
counter-balance to prevailing portrayals of a coherent and culturally uniform Japanese Jomon, a single and homogenous 'rice' Neolithic in China, or a general Neolithic stage that can be tracked across all the prehistoric archaeology of the Russian Far East.

But how do these NEOMAP conclusions feed back into debates in European archaeology? The archaeology of much of East Asia appears to be defined by an equally complex but much less integrated process of Neolithization, very unlike some of the earlier formulations of a general Neolithic 'package' that still tend to prevail in much of Europe. Such different patterns probably also extend right across the intervening reaches of inner Eurasia, as evidenced by widespread and pre-agricultural uses of pottery by hunter-gatherers (Jordan and Zvelebil 2009). The trend towards particularistic case-studies of the European Neolithic may thus be losing sight of the exciting new scope for larger-scale, more explicitly comparative reflections on the wide range of distinctive Neolithization trajectories being played out across Eurasia. Was Europe, with its distinct package of Neolithic traits, in fact the great exception to many of these much wider Eurasian trends? If so, how best to explain the specific features of the unique European Neolithization trajectory against the wider backdrop of the Eurasian continent?

\section{Conclusions}

This special issue aims to trigger fresh reflections on the long-standing debates surrounding some of the major cultural transformations that define the earlier and middle phases of the Holocene. Specifically, it aims to explore new ways of researching and understanding these dynamic cultural transformations by looking at Neolithization as a long-term and inherently contingent process. Overall, the NEOMAP Project has confirmed that application of models and theory used widely in European Neolithic studies to the archaeology of East Asia leads to the conclusion that there was clearly scope for multiple Neolithic trajectories. In other words, there existed many potentially different outcomes of Neolithization, and the inter-play of these many factors resulted in numerous highly-contingent local sequences.

The conceptual and empirical utility of the NEOMAP approach within East Asian archaeology has been made clear. This research was never conceived as a clumsy and simplistic exercise in imposing European models on to different cultural sequences, and the flexibility of the cultural landscape approach, combined with the unique internal characteristics of the East Asian sequences, have militated against this potential danger. Instead, NEOMAP aimed to generate as many new insights, understandings and questions as possible. The overall outcome has been to demonstrate that the Neolithization of East Asia was a far more complex - and diverse and contingent - phenomenon than has traditionally been assumed, but nevertheless one whose legacy has been of fundamental importance in shaping the cultural heritage and modern cultural landscapes of the wider region.

Finally, what inspiration can European archaeologists draw from these papers and from the NEOMAP Project more generally? Reviewing the assumptions, details and implications of their European datasets, models and general traditions of enquiry against this wider Eurasian backdrop, they should increasingly see that the Neolithic of Europe was only one very specific kind of Neolithic. Clearly, there were several alternative pathways to Neolithization, and many alternative histories to each of its constituent elements.

So why did the European Neolithic develop along its own highly-specific trajectory, when contemporary communities in the broadly analogous landscapes and environments of East Asia developed along very different pathways? Could it be time for European 
archaeologists to look up from their particularistic accounts of on-the-ground agency, and engage with some of the deeper implications of these comparative perspectives?

Examining the experiences of specific households and communities within one period of historical change is an important endeavour, but explaining how and why these microscale dynamics fed into, and ultimately generated, the specific macro-scale trajectory of the European Neolithic is quite another task. Combining these contrasting scales of analysis, and explaining how such different Neolithization trajectories were able to play out across Eurasia is emerging as central task of any forthcoming attempt to write a fully 'world' prehistory of some of the Holocene's most important cultural transformations.

Acknowledgments This special issue is an output of the international NEOMAP Project ('Neolithisation and Modernisation: Landscape History on East Asian Inland Seas', see: http://www.chikyu.ac.jp/rihn_e/ project/H-04.html), which was based at the Research Institute of Humanity and Nature (RIHN) (http://www. chikyu.ac.jp/rihn_e/about.html) between 1 April 2005 and 31 March 2012 (Project Code: H-04). It was funded by the Japanese Ministry of Education, Culture, Sports, Science and Technology (MEXT). The NEOMAP Project Leader was Junzo Uchiyama. The NEOMAP Team would like to express their deep gratitude to RIHN/MEXT for funding and hosting the project. Most of the papers in this special issue were also presented in a session entitled 'Landscape Neolithization along East Asian Inland Seas', organised by NEOMAP at the 2009 meeting of the Society for American Archaeology in Atlanta, Georgia, USA.

\section{References}

Ammerman, A. J., \& Cavalli Sforza, L. L. (1984). The Neolithic transition and the genetics of population in Europe. Princeton, NJ: Princeton University Press.

Barrett, J. C. (1994). Fragments from Antiquity: An archaeology of social life in Britain, 2900-1200 BC. Oxford: Blackwell.

Bender, B. (Ed.). (1993). Landscape: Politics and perspectives. London: Routledge.

Bender, B. (2006). Place and landscape. In C. Tilley, W. Keane, S. Küchler, M. Rowlands, \& P. Spyer (Eds.), Handbook of material culture (pp. 303-314). London: Sage.

Bradley, R. (1998). The significance of monuments. London: Routledge.

Carmichael, M. L., Hubert, J., Reeves, B., \& Schanche, A. (Eds.). (1994). Sacred sites, sacred places. London: Routledge.

Childe, V. G. (1957). The dawn of European civilisation (6th ed.). St Albans: Paladin.

Cho, D., \& Ko, I. (2009). Hunter-gatherer ceramics of Neolithic Korea. In P. Jordan \& M. Zvelebil (Eds.), Ceramics before farming: The dispersal of pottery among prehistoric Eurasian hunter-gatherers (pp. 149-166). Walnut Creek, CA: UCL Institute of Archaeology/Left Coast Press.

Craig, O. E., Saul, H., Lucquin, A., Nishida, Y., Taché, K., Clarke, L., et al. (2013). Earliest evidence for the use of pottery. Nature, 496(7445), 351-354. doi:10.1038/nature12109.

David, B., Lamb, L., \& Kaiwari, J. (2014). Landscapes of mobility. In C. Cummings, P. Jordan, \& M. Zvelebil (Eds.), The Oxford handbook of the archaeology and anthropology of hunter-gatherers (pp. 1163-1190). Oxford: Oxford University Press.

David, D., \& Thomas, J. (Eds.). (2008). Handbook of landscape archaeology. Walnut Creek, CA: Left Coast Press.

Edmonds, M. (1999). Ancestral geographies of the Neolithic: Landscapes, monuments and memory. London: Taylor \& Francis.

Gibbs, K., \& Jordan, P. (2013). Bridging the Boreal Forest: Siberian archaeology and the emergence of pottery among prehistoric hunter-gatherers of northern Eurasia. Sibirica, 12(1), 1-38. doi:10.3167/sib. 2013.120101.

Habu, J. (2004). Ancient Jomon of Japan. Cambridge: Cambridge University Press.

Habu, J. (2014). Post-Pleistocene transformations of hunter-gatherers in East Asia: The Jomon and Chulmun. In V. Cummings, P. Jordan, \& M. Zvelebil (Eds.), The Oxford handbook of the archaeology and anthropology of hunter-gatherers (pp. 507-520). Oxford: Oxford University Press.

Higgs, E. S., \& Jarman, M. R. (1969). The origins of agriculture: A reconsideration. Antiquity, 43, 31-41.

Hodder, I. (1990). The domestication of Europe. Oxford: Blackwell.

Hosoya, L. A. (2002). Sacred commonness: An archaeobotanical approach to the social importance of rice in the Japanese prehistoric state formation. Unpublished PhD dissertation, University of Cambridge. 
Hosoya, L. A. (2008a). Storage facilities and the agricultural 'routine-scape' in Japanese prehistory: Archaeological and ethnographic approaches. In A. N. Popov \& J. Uchiayama (Eds.), Neolithic and Neolithisation in the Japanese Sea Basin (pp. 236-246). Vladivostok: Far Eastern University.

Hosoya, L. A. (2008b). Kome to kura: Bali-to inasaku shakai no minzoku chosa (Rice and granaries: Ethnoarchaeological study of Bali rice farming society). In T. Ebisawa (Ed.), Koza Suito Bunka Kenkyu IV: Bali-to no Suito Bunka to Girei (Studies on paddy rice culture IV: Bali rice farming culture and the rituals) (pp. 87-111). Tokyo: Waseda University Research Institute for Paddy Rice Culture (in Japanese).

Hosoya, L. A. (2009a). Yakihata no raifu saikuru to konsai-rui no chozo sisutemu: Papua New Guinea no jirei ni miru 'noko shakai' no tayosei (Life cycle based on swidden agriculture and tuber crop storage system: Case study in Papua New Guinea and diversity of farming culture). In Y.-I. Sato \& E. Kimura (Eds.), Yurashia Noko-shi 4: Samazama na Saibai Shokubutu to Noko Bunka (The history of Eurasian agriculture 4: Diversity in cultivars and farming system) (pp. 185-228). Kyoto: Rinsen Shoten (in Japanese).

Hosoya, L. A. (2009b). Sacred commonness: An archaeobotanical approach to Yayoi social stratification: The 'central building model' and Osaka Ikegami Sone site. In K. Ikeya, H. Ogawa, \& P. Mitchell (Eds.), Interaction between hunter-gatherers and farmers: From prehistory to present. Senri Ethnological Studies (Vol. 73, pp. 99-177). Osaka: National Museum of Ethnology.

Hosoya, L. A. (2010). 'Noko gijyutsu' to shite no saishi: Amami Oshima no jirei kara miru 'noko kankyo' to saishi no yakuwari (Ritual as an 'agricultural technology': The role of rituals and 'agricultural environment' in the examples of Amami Oshima Island). Kokugakuin Daigaku Dento Risachi Senta Kenkyu Kiyo (Bulletin of Research Center for Traditional Culture, Kokugakuin University), 2, $125-141$.

Hudson, M. J. (2014). The ethnohistory and anthropology of 'modern'hunter-gatherers: North Japan (Ainu). In V. Cummings, P. Jordan, \& M. Zvelebil (Eds.), The Oxford handbook of the archaeology and anthropology of hunter-gatherers (pp. 507-520). Oxford: Oxford University Press.

Imamura, K. (1996). Prehistoric Japan: New perspectives on insular East Asia. London: UCL Press.

Ingold, T. (2000). The perception of the environment: Essays in livelihood, dwelling and skill. London: Routledge.

Jordan, P. (2011). Landscape and culture in northern Eurasia: An introduction. In P. Jordan (Ed.), Landscape and culture in northern Eurasia (pp. 17-45). Walnut Creek, CA: UCL Institute of Archaeology/Left Coast Press.

Jordan, P. (2014). The ethnohistory and anthropology of 'modern' hunter-gatherers. In V. Cummings, P. Jordan, \& M. Zvelebil (Eds.), The Oxford handbook of the archaeology and anthropology of huntergatherers (pp. 903-917). Oxford: Oxford University Press.

Jordan, P., \& Zvelebil, M. (Eds.). (2009). Ceramics before farming: The dispersal of pottery among prehistoric Eurasian hunter-gatherers. Walnut Creek, CA: UCL Institute of Archaeology/Left Coast Press.

Kaner, S. (2009). Long-term innovation: The appearance and spread of pottery in the Japanese Archipelago. In P. Jordan \& M. Zvelebil (Eds.), Ceramics before farming: The dispersal of pottery among prehistoric Eurasian hunter-gatherers (pp. 93-119). Walnut Creek, CA: UCL Institute of Archaeology/ Left Coast Press.

Lubbock, J. (1865). Pre-historic times. London: Williams \& Norgate.

Nakamura, O. (2008). Shakai Kaiso (Social stratification). In Y. Kosugi, Y. Taniguchi, Y. Nishida, K. Mizunoe, \& K. Yano (Eds.), Jomon Jidai no Kohkogaku 10: Hito to Shakai (Archaeology of the Jomon Period 10: People and society) (pp. 145-155). Tokyo: Doseisha (in Japanese).

Price, T. D., \& Brown, J. A. (Eds.). (1985). Prehistoric hunter-gatherers: The emergence of cultural complexity. Orlando: Academic Press.

Seguchi, S. (2014). Landscape 'Neolithization' among the Hunter-Fisher-Gatherers of Lake Biwa, Central Japan. Journal of World Prehistory. doi:10.1007/s10963-014-9078-9.

Taavitsainen, J.-P. (2014). Hunter-gatherer transformations in northern Europe after 1500 AD. In V. Cummings, P. Jordan, \& M. Zvelebil (Eds.), The Oxford handbook of the archaeology and anthropology of hunter-gatherers (pp. 1071-1090). Oxford: Oxford University Press.

Thomas, J. (1988). Neolithic explanations revisited: The Mesolithic-Neolithic transition in Britain and south Scandinavia. Proceedings of the Prehistoric Society, 54, 59-66.

Thomas, J. (1999). Understanding the Neolithic. London: Routledge.

Tilley, C. (1994). A phenomenology of landscape: Places, paths and monuments. London: Routledge.

Tilley, C. (1996). An ethnography of the Neolithic. Cambridge: Cambridge University Press.

Trigger, B. G. (2006). A history of archaeological thought (2nd ed.). Cambridge: Cambridge University Press. 
Uchiyama, J. (2009). Jomon no katachi to Yayoi no katachi (Jomon style and Yayoi style). In J. Uchiyama, K. Lindström, C. Zeballos, \& O. Nakamura (Eds.), NEOMAP interim report 2008: Neolithisation and modernisation: Landscape history on East Asian inland seas (pp. 139-154). Kyoto: Research Institute for Humanity and Nature (RIHN).

Uchiyama, J. (2011). Jomon and Yayoi Styles: A worldview transition within Neolithisation in the Japanese Archipelago. In T. Peil (Ed.), The space of culture: The place of nature in Estonia and beyond. Approaches to culture theory series (Vol. 1, pp. 136-152). Tartu: Tartu University.

Ucko, P., \& Layton, R. (Eds.). (1999). The archaeology and anthropology of landscape: Shaping your landscape. London: Routledge.

Underhill, A. P., \& Habu, J. (2006). Early communities in East Asia. In M. T. Stark (Ed.), Archaeology of Asia (pp. 121-148). Malden, MA: Blackwell.

Whittle, A. (2007). Going over: People and their times. In A. Whittle \& V. Cummings (Eds.), Going over: The Mesolithic-Neolithic transition in NW Europe (pp. 617-628). London: British Academy.

Whittle, A., \& Cummings, V. (2007). Introduction: Transitions and transformations. In A. Whittle \& V. Cummings (Eds.), Going over: The Mesolithic-Neolithic transition in NW Europe (pp. 1-4). London: British Academy.

Zvelebil, M. (Ed.). (1986). Hunters in transition: Mesolithic societies of temperate Eurasia and their transition to farming. Cambridge: Cambridge University Press.

Zvelebil, M. (2000). The social context of the agricultural transition in Europe. In C. Renfrew \& K. Boyle (Eds.), Archaeogenetics: DNA and the population prehistory of Europe (pp. 57-79). Cambridge: McDonald Institute for Archaeological Research.

Zvelebil, M. (2003). Enculturation of Mesolithic landscapes. In L. Larsson, H. Kindgren, K. Knutsson, D. Loeffler, \& A. Åkerlund (Eds.), Mesolithic on the move (pp. 65-73). Oxford: Oxbow.

Zvelebil, M. (2004). Who were we 6000 years ago? In search of prehistoric identities. In M. Jones (Ed.), Traces of ancestry: Studies in honour of Colin Renfrew (pp. 41-60). Cambridge: McDonald Institute for Archaeological Research.

Zvelebil, M. (2005). Homo habitus: Agency, structure and the transformation of tradition in the constitution of the TRB foraging-farming communities in the north European plain (ca 4500-2000 BC). Documenta Praehistorica, XXXII, 87-101.

Zvelebil, M. (2006). Mobility, contact, and exchange in the Baltic Sea basin 6000-2000 BC. Journal of Anthropological Archaeology, 25, 178-192.

Zvelebil, M. (2008). Innovating hunter-gatherers: The Mesolithic in the Baltic. In G. Bailey \& P. Spikins (Eds.), Mesolithic Europe (pp. 18-59). Cambridge: Cambridge University Press. 